\title{
Stepwise or couple antenatal carrier screening for cystic fibrosis?: women's preferences and willingness to pay
}

\author{
Zosia Miedzybrodzka, June Semper, Phil Shackley, Mona Abdalla, Cam Donaldson
}

\begin{abstract}
Several antenatal cystic fibrosis carrier screening trials have offered women testing by either the stepwise or the couple method. In this study, both approaches were described to women attending an antenatal clinic, who were then asked which method they preferred. An estimate of the value to women of each type of test was also ascertained using a "willingness to pay" (WTP) method. Of 450 women, $279(62 \%)$ preferred stepwise screening, $117(26 \%)$ preferred couple screening, and $54(12 \%)$ had no preference. Mean WTP for stepwise screening was $£ 19$ (95\% CI $£ 17.50-£ 20.50)$, and that for couple screening was $£ 18(95 \%$ CI $£ 16.50-£ 19.50)$. The majority of women preferred stepwise screening although the average WTP for each method was similar.
\end{abstract}

(f Med Genet 1995;32:282-283)

Aberdeen,

Department of

Obstetrics and

Gynaecology,

Aberdeen Maternity

Hospital, Foresterhill,

Aberdeen AB9 2ZD,

UK

Z Miedzybrodzka

Health Economics

Research Unit,

University Medical

Buildings,

Foresterhill, Aberdeen

AB9 2ZD, UK

J Semper

P Shackley

C Donaldson

Health Services

Research Unit,

University Medical

Buildings,

Foresterhill, Aberdeen

AB9 2ZD, UK

M Abdalla

Correspondence to: Dr Miedzybrodzka.

Received 22 August 1994 Revised version accepted for publication 6 December 1994

Two different approaches to antenatal carrier screening for cystic fibrosis (CF) have been proposed. ${ }^{12}$ With stepwise screening, women attending the clinic are offered a test. If a carrier is found, testing is offered to her partner after genetic counselling. Carriers may suffer anxiety while awaiting their partner's test result, but are informed of their individual risk status, which may be used to inform relatives or to allow new partners to be tested. ${ }^{13}$ Couple screening was devised to avoid carriers' anxiety if the partner tests negative. ${ }^{24}$ With this method, samples are taken from both partners and couples are given a positive result only if both are carriers.

Other studies have assessed anxiety, false reassurance, and acceptability among women who have undergone testing by one or other of the screening approaches. ${ }^{13-5}$ In this study, we described both approaches to pregnant women who had not been offered CF carrier testing. Women were asked which method they pre-

Table 1 Matching of preference and WTP

\begin{tabular}{lllll}
\hline \multirow{2}{*}{ Preference } & \multicolumn{3}{l}{$\begin{array}{l}\text { Is willingness to pay (WTP) for stepwise } \\
>\text { } W T P \text { for couple screening? }\end{array}$} & \\
\cline { 2 - 5 } & No (\%) & Equal (\%) & Yes (\%) & Total (\%) \\
\hline Stepwise & $61(17)$ & $99(28)$ & $62(17)$ & $222(62)$ \\
Couple & $78(21)$ & $16(4)$ & & $94(26)$ \\
No preference & $21(6)$ & $22(6)$ & 1 & $44(12)$ \\
Total & $160(44)$ & $137(38)$ & $63(18)$ & $360(100)$ \\
\hline
\end{tabular}

90 women did not respond to this question. ferred and an attempt was made to measure the value of the two screening approaches. "Value" is determined by what people are prepared to sacrifice to obtain a particular "commodity", such as a screening test. One way of measuring such value is to ascertain the maximum amount people would be "willing to pay" for the commodity. Though still experimental, the use of "willingness to pay" (WTP) measures to assess the value of health care interventions is growing. ${ }^{6}$

\section{Subjects, methods, and results}

Women attending Aberdeen Maternity Hospital antenatal clinics between 15.11.93 and 16.12.93 were asked to complete a questionnaire. They were asked if they would have a CF carrier test if it was available, which of the testing approaches they preferred, and what their maximum "willingness to pay" was for each of the approaches. ${ }^{5}$ Information was provided about CF and the two approaches to screening. Previous experience with WTP led us not to suggest WTP values from which the respondent could select; respondents were asked to write their WTP in a space provided in the questionnaires. ${ }^{5}$ This is called an "open ended" approach.

Questionnaires were completed by 450 women. Sixty-two percent preferred stepwise screening, $26 \%$ preferred couple screening, and $12 \%$ had no preference.

WTP responses did not always reflect the stated preference for method of testing (table 1). Such WTP responses were considered invalid and were excluded from the WTP analysis, as most of these women stated they had attempted to estimate the cost of the test rather than the value to them. The final WTP analyses were based on the remaining 277 responses. WTP is not an exact measure, so WTP responses of women who expressed a preference for one approach, but who had equal WTP for the two methods were still included. If the most important factor is to have a test of some sort, then it is not surprising that WTP might be the same for each method. These women may have a slight preference for one or other method, but they are not willing to pay more for their preferred method.

The mean WTP value for stepwise screening was $£ 19$ (95\% CI $£ 17.50-£ 20.50)$ while that for couple screening was $£ 18 \quad(16.50$ $£ 19.50)$. Overall the WTP for stepwise screening was $6 \%$ greater than that for couple screening. This difference was not statistically 
Table 2 Intensity of preference for different screening approaches

\begin{tabular}{lll}
\hline Group & $\begin{array}{l}\text { Mean ratio of WTP for the two } \\
\text { approaches }\end{array}$ & $95 \%$ CI of WTP ratio \\
\hline All valid cases & WTPS/WTPC $* 1.06$ & $0.94-1 \cdot 19$ \\
Preferred stepwise & WTPS/WTPC $=1.63$ & $1 \cdot 42-1 \cdot 87$ \\
Preferred couple & WTPC/WTPS $=1.98+$ & $1.66-2.36$ \\
No preference & WTPS/WTPC $=1.00$ & $0 \cdot 71-1.44$ \\
\hline
\end{tabular}

*WTPS = willingness to pay for stepwise screening, WTPC = willingness to pay for couple screening.

† For purposes of comparison of intensity of preference of those preferring couple screening with the intensity of preference of those preferring stepwise screening, it is more relevant to divide WTPC by WTPS rather than divide WTPS by WTPC (WTPS/WTPC equals 0.51).

significant (table 2). Respondents who preferred stepwise screening were, on average, willing to pay $63 \%$ more for that method. The minority who preferred couple screening were willing to pay $98 \%$ more for their chosen method. The difference in WTP for chosen approach was not statistically significant at the $5 \%$ level $(1 \cdot 63 / 1 \cdot 98=0 \cdot 83 ; 95 \%$ CI for ratio $0 \cdot 66-1 \cdot 03)$.

Stepwise regression analysis was used to identify predictors of $\log$ WTP values for each screening method. Possible predictors were age, marital status, age at leaving full time education, home ownership, social class, gestation, number of children in the family, and whether there was a family history of CF.

Social class was the only significant predictor at the 5\% level for log WTP for stepwise screening (adjusted $R^{2}=0.01 ; n=266$ ). Being single, as opposed to being married or cohabiting, was the only significant predictor of couple screening (adjusted $\mathrm{R}^{2}=0.03$ ). However, the ratio of WTPS/WTPC was not associated with age, marital status, age at leaving full time education, home ownership, social class, number of children in the family, or family history of CF. Interestingly, gestation was positively associated with WTPS/WTPC.

\section{Discussion}

More women prefer stepwise screening, but those who prefer couple testing feel at least as strongly about their chosen approach. To provide for the needs of this minority, a choice of testing approach might be considered optimal, although offering such choice would probably be impractical.

Women may prefer stepwise to couple screening as it avoids the need for them to obtain a sample from their partner, or because they may wish to know individual carrier status. They may want this information for its own sake, or to inform relatives, or for future pregnancies with different partners, or simply because they dislike the idea of doctors (or health services) withholding information.

There are limits to the validity of the WTP approach used. Because of invalid responses, values of only 277 women were used in the WTP analysis, and so the views of 173 women were not accounted for. Currently, techniques are being devised to attempt to overcome this problem.

A recent randomised trial of stepwise versus couple screening found that stepwise screening is associated with less anxiety and false reassurance. ${ }^{3}$ The above data on preference may be taken together with the trial data to conclude that stepwise screening is the better approach for implementation.

We would like to thank Professor Allan Templeton and Drs Marion Hall, Neva Haites, and John Dean for helpful comments, the staff of Aberdeen Maternity Hospital Antenatal Clinic fo all their help, and Aberdeen Maternity Hospital Senior Staff Committee for permission to use their patients in the study. This study was funded by the Scottish Office Home and Health Department (SOHHD) those of the authors, not SOHHD.

1 Mennie ME, Gilfillan A, Compton M, et al. Prenatal screening for cystic fibrosis. Lancet 1992;340:214-16.

2 Wald NJ. Couple screening for cystic fibrosis. Lancet 1991 338:1318-19.

3 Miedzybrodzka Z, Hall M, Mollison J, et al. Antenatal carrie screening for cystic fibrosis: randomised trial of step-wise vs couple screening. $B M \mathcal{F} 1995 ; 310: 353-7$.

4 Livingstone $J$ Axton RA, Gifillan A et al Antenatal screenin for cystic fibrosis: a trial of the couple method. $B M F 1994$ 308:1459-62.

5 Miedzybrodzka $Z$, Shackley $P$ Abdalla $M$, Donaldson $C$ Counting the benefits of screening: a pilot study of will ingness to pay for antenatal carrier screening for cystic ingness to pay for antenatal carrier

6 Gafni A Willingness-to-pay as a measure of benefits: relevant questions in the context of public decision making about health care programs? Med Care 1990;29:1246-52. 